\title{
METODOLOGIA PARA AVALIAÇÃO DO ESCOAMENTO SUBSUPERFICIAL EM VERTENTES
}

\author{
METHODOLOGY FOR EVALUATING SUBSUPERFICIAL RUNOFF IN STRANDS
}

\author{
METODOLOGIA PARA EVALUACIÓN DE ESCOJAMIENTO \\ SUBSUPERFICIAL EN LAS VERTENTES
}

Flávio Alves de Sousa - Universidade Estadual de Goiás - Iporá - Goiás - Brasil

flaueg@hotmail.com

\section{Resumo}

0 estudo teve como objetivo criar uma proposta metodológica para examinar a dinâmica do fluxo subsuperficial da água nas vertentes, considerando que a mesma possa ser aplicada em todo tipo de domínio climático e tipo de solo/cobertura, exceto em locais onde predominam coberturas constantes por neve ou gelo. Para tanto, foram realizados trabalhos de campo e análises de laboratório, sendo que a ideia central é avaliar quanto é escoado superficialmente após um evento chuvoso e quanto flui em subsuperfície ao nível de até $100 \mathrm{~cm}$ e, finalmente, predizer quanto é infiltrado para o lençol freático. 0 experimento foi desenvolvido em uma vertente com área de $16.657 \mathrm{~m}^{2}$ localizada na fazenda da Universidade Federal de Goiás, Campus de Jataí-G0. A vertente analisada apresenta declividade de $3,7^{\circ}$ onde predomina Latossolo Vermelho-Escuro distroférrico com textura franco-argilosa. Utilizou-se durante o experimento, que durou de agosto de 2017 a janeiro de 2018, medidas do escoamento superficial, coleta de amostras indeformadas de solos, avaliação da umidade dos solos em profundidades de 30,60 e $100 \mathrm{~cm}$, e foram registrados os volumes de chuva durante o período do experimento. Do total de chuva que chegou à superfície, $20,444 \%$ escoaram, $61,78 \%$ foram armazenados no solo, $17,77 \%$ infiltraram para o lençol freático e $0,006 \%$ fluíram em subsuperfície ao longo da vertente.

Palavras-chave: Escoamento. Infiltração. Experimento.

\section{Abstract}

The objective of this study was to create a methodological proposal to examine the subsurface flow dynamics of the waters in the slopes, considering that it can be applied in all types of climatic domain and the type of soil / cover, except in places where dominate snow or ice. For that, fieldwork and laboratory analyzes were performed and the main idea is to evaluate how much is drained superficially after a rainy event and how much is drained, how much it flows in the subsurface until the level of $100 \mathrm{~cm}$ and, finally, to predict how much is infiltrated to the water table. The experiment was executed in an area of $16,657 \mathrm{~m}^{2}$ located on the farm of the Goiás Federal University, Jataí Campus, Goiás State, Campus Goiás state. The strand has a slope of $3.7^{\circ}$ with predominance of a Distroferric Dark Red Latosol with Franco-loamy texture. Measurements of surface runoff, collection of undisturbed soil samples, soil moisture assessments at depths of 30,60 and $100 \mathrm{~cm}$ were determined during the experiment, as well as rainfall volumes were recorded across the experimental length. Out of the total rainfall that reached the surface, $20.444 \%$ was drained, $61.78 \%$ was stored in the soil, $17.77 \%$ was infiltrated into the water table, and $0.006 \%$ flowed into the subsurface.

Keywords: Flow. Infiltration. Experiment.

\section{Resumen}

El objetivo de este estudio fue crear una propuesta metodológica para examinar la dinámica del flujo subsuperficial de las aguas en las laderas, considerando que se puede aplicar en todos los tipos de dominio climático y el tipo de suelo / cubierta, excepto en lugares donde domina la nieve e hielo Para ello, se realizaron análisis de campo y de laboratorio y la idea principal es evaluar cuánto se drena superficialmente después 
de un evento lluvioso y cuánto se drena, cuánto fluye en el subsuelo hasta el nivel de $100 \mathrm{~cm}$ y, finalmente, para predecir Cuánto se infiltra en el nivel freático. El experimento se llevó a cabo en un área de 16,657 m2 ubicado en la finca de la Universidad Federal de Goiás, Campus de Jataí, Estado de Goiás, Estado de Goias. La hebra tiene una pendiente de $3.7^{\circ}$ con predominio de un Latosol Rojo Oscuro Distroférrico con textura francofranca. Durante el experimento se determinaron las mediciones de la escorrentía superficial, la recolección de muestras de suelo no perturbado, las evaluaciones de humedad del suelo a profundidades de 30,60 y 100 $\mathrm{cm}$, así como los volúmenes de lluvia a lo largo de la duración experimental. Del total de lluvia que alcanzó la superficie, el $20,444 \%$ se drenó, el $61,78 \%$ se almacenó en el suelo, el $17,77 \%$ se infiltró en el nivel freático y el $0,006 \%$ se vertió en el subsuelo.

Palabras clave: Flujo. Infiltración. Experimento.

Introdução

Quando a água da chuva cai no solo ela pode seguir dois caminhos. Um deles é o escoamento superficial, cujo volume depende da intensidade das chuvas, da declividade do terreno, do grau de saturação dos solos, da capacidade de infiltração e da cobertura vegetal. O outro é a infiltração, que também depende das mesmas variáveis supracitadas. Todavia, a infiltração pode se dividir em dois ramos: o escoamento subsuperficial que flui no nível das raízes em direção ao fundo de vale conforme a inclinação da vertente; e outro que se prolonga verticalmente até o lençol freático.

O volume da precipitação e sua intensidade influenciam diretamente na infiltração e no escoamento superficial. Após uma chuva, a parte superior dos solos tende a estar mais saturada que as camadas mais profundas e nesse caso, o excedente das partes superiores tende a fluir para as partes inferiores (Lepsch, 2011, p.156). Cada solo responde de maneira diferente a esse processo de acordo com as suas condições físicas naturais, ou quando alteradas pelo uso humano.

Brandão et al. (2006, p. 14) lembram que a água que se infiltra é fundamental para o balanço da água na "zona radicular das culturas", pois aquela que fica retida no solo alimenta as plantas nos períodos mais secos.

O fluxo considerado como prioridade neste estudo corresponde ao escoamento subsuperficial, ou seja, aquele que flui logo abaixo da superfície, ao nível do sistema radicular das plantas e, conforme aponta Valente e Gomes (2005, p.25), a uma profundidade que pode chegar a $1,5 \mathrm{~m}$. O escoamento subsuperficial está no limiar entre o escoamento superficial e o escoamento subterrâneo, podendo em alguns pontos do terreno interceptar a superfície e engrossar o fluxo superficial, ou mesmo fluir verticalmente a partir de sua base para o lençol freático. 
A mensuração do escoamento subsuperficial depende da forma da encosta, já que a encosta muito inclinada favorece ao escoamento superficial, e quando planas, predomina a infiltração subterrânea. Por outro lado, em condições alteradas por compactação, os poros selados pelo impacto das gotas favorecem a erosão laminar (Bertoni; Lombardi Neto, 1990, p.75). Nesse sentido, é preciso avaliar encostas onde o escoamento superficial e a infiltração subterrânea apresente alguma correlação.

Os fluxos superficiais e subsuperficiais são mais eficientes durante os períodos chuvosos, quando os solos tendem a estar mais saturados. Durante os períodos de estiagem, o fluxo da infiltração tende a ser mais verticalizado em direção ao lençol freático, devido ao deslocamento da água das camadas superiores para as inferiores do solo (Lepsch, 2011, p.156). Nos solos quando secos, a água tende a ficar retida pela matriz do solo, aumentando a capacidade de adsorção da água em suas partículas (Pott, 2001, p.3).

Embora se conheça bem os caminhos da água em uma encosta, não há, até o momento, uma explicação de como ocorre o escoamento em subsuperfície. Apesar de haver equações que estimam o volume escoado e infiltrado, não se sabe exatamente o volume infiltrado até o ponto de abastecimento do lençol freático, nem aquele que flui abaixo do sistema radicular das plantas no sentido da inclinação da encosta.

Diante disso, realizou-se com o presente trabalho, uma investigação que pudesse resultar em uma proposta metodológica para estimar este fluxo, levando-se em conta as principais variáveis que influenciam no processo de escoamento/infiltração da água ao longo de uma vertente.

A área escolhida para o experimento foi uma fração de vertente localizada no Campus Jatobá da Regional Jataí na Universidade Federal de Goiás, cuja localização é $17^{\circ} 55^{\prime} 42^{\circ}$ S - 51 $42^{\circ}$ ' 48” W. A referida área apresenta uma declividade média $3,7^{\circ}$ (Figura 1). 
Figura 1 - Localização da área de estudo

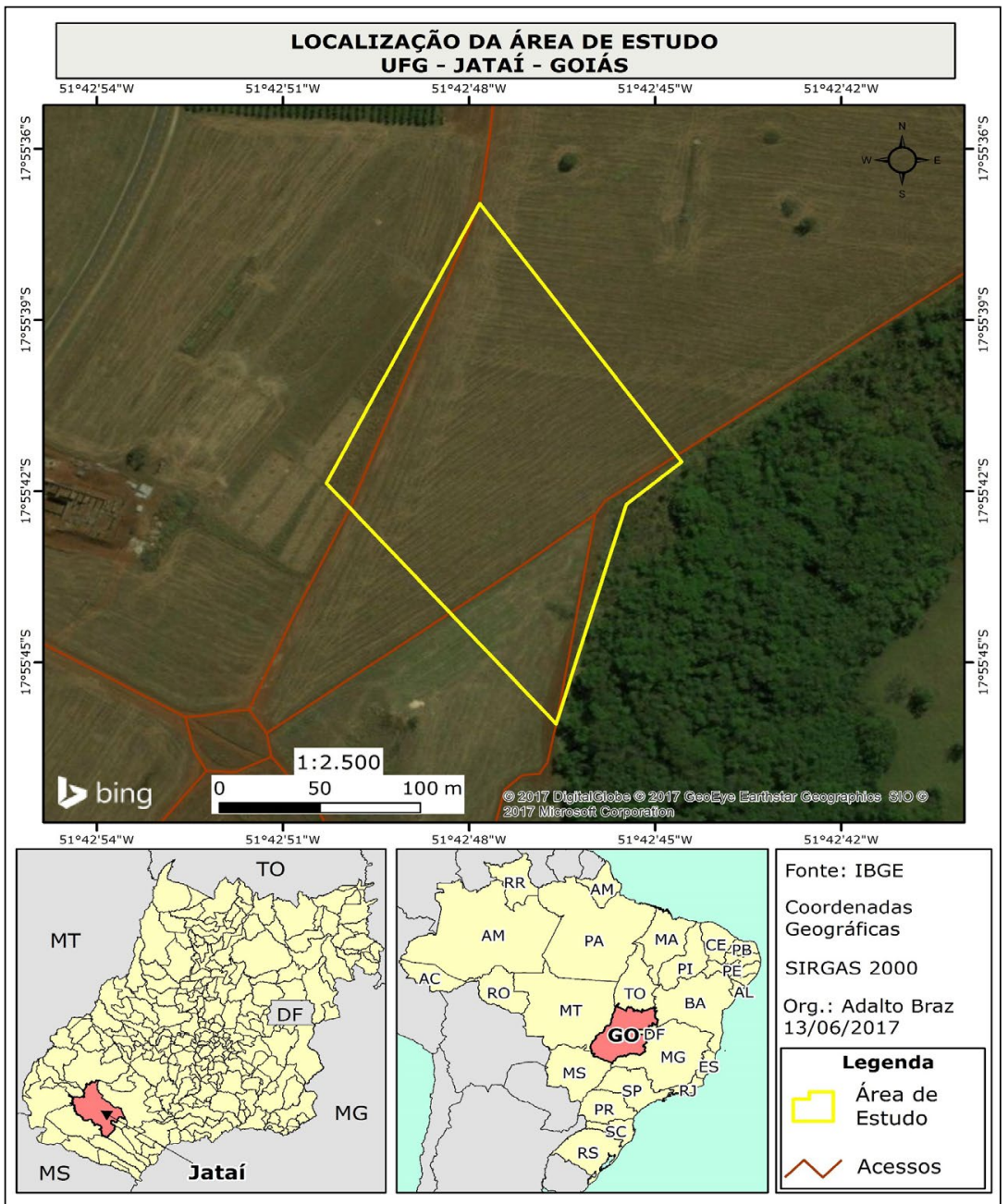

Fonte: Sousa (2018). 
Procedimentos metodológicos

O desenvolvimento do projeto contou com etapas de campo e laboratório que nortearam toda a trajetória da pesquisa. Os procedimentos metodológicos estão descritos abaixo.

Primeiramente, foi realizado um estudo sobre o fluxo subsuperficial da água da chuva na vertente. Para isso, foi escolhida uma vertente com declividade de $3,7^{\circ} \mathrm{em}$ uma área de $16.657 \mathrm{~m}^{2}$. A escolha da área se deu em função da mesma apresentar uma tendência à infiltração sem deixar de apresentar condições para o deslocamento lateral em subsuperfície e para o escoamento superficial (runoff).

Após seleção da vertente, deu-se início aos experimentos, ainda no período de estiagem, e assim foram tomadas as seguintes providências: a) Determinação da declividade média da encosta, que neste estudo foi feita com base no perfil topográfico da vertente utilizando-se o Google Earth como referência; b) Foram feitos os cálculos da área da encosta e do volume da encosta com base na equação 1, que considerou a largura da encosta (L), o comprimento da encosta (C) e a profundidade (1m) para o cálculo do volume da encosta.

$$
V_{\text {enc }}=L \times C \times 1 m
$$

Onde: $\boldsymbol{V}_{\text {enc }}=$ volume da encosta.

A coleta de água na calha serviu para mensurar o quanto escoou superficialmente após os eventos chuvosos ao longo do experimento. A cada coleta foram registrados os volumes de chuvas registradas até a o momento da leitura, bem como o volume escoado.

Os volumes escoados foram utilizados para estimar o escoamento em toda a área da encosta. 
Figura 2 - Sistema coletor de água por escoamento superficial.

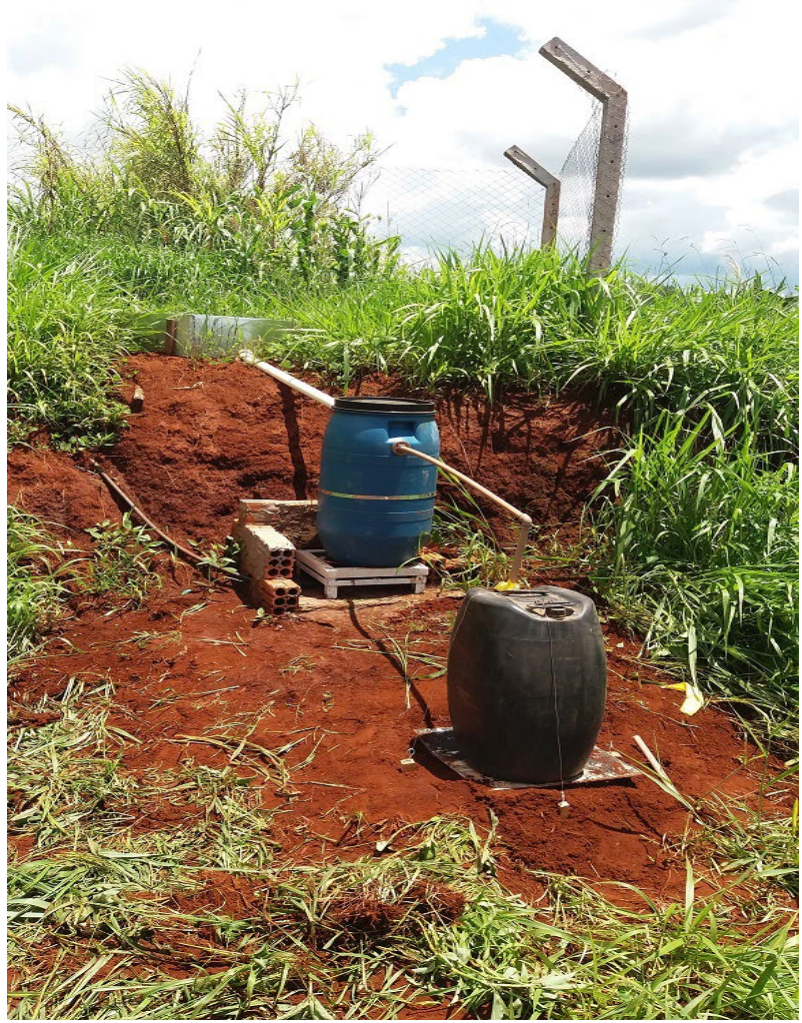

Fonte: Do autor (2018).

Os dados de chuva foram obtidos junto à estação meteorológica automática do Instituto Nacional de Meteorologia (INMET), Estação A016Jataí, posicionada a 700 metros da área de estudo.

Outro procedimento foi a determinação da umidade do solo. Para tal, foram coletadas amostras indeformadas a profundidades de 30, $60 \mathrm{e}$ $100 \mathrm{~cm}$. As amostras foram coletadas com trado tipo TAI, para coleta de amostras indeformadas por anéis volumétricos. Foram coletadas amostras em três linhas: topo, meio e base da vertente, sendo três pontos em cada linha e três profundidades em cada ponto, num total de 27 amostras. Os cilindros com as amostras foram acondicionados em papel alumínio e saco plástico vedado e etiquetado e conduzidos ao laboratório. 
Figura 3 - Trado tipo TAl, utilizado na coleta de amostras indeformadas

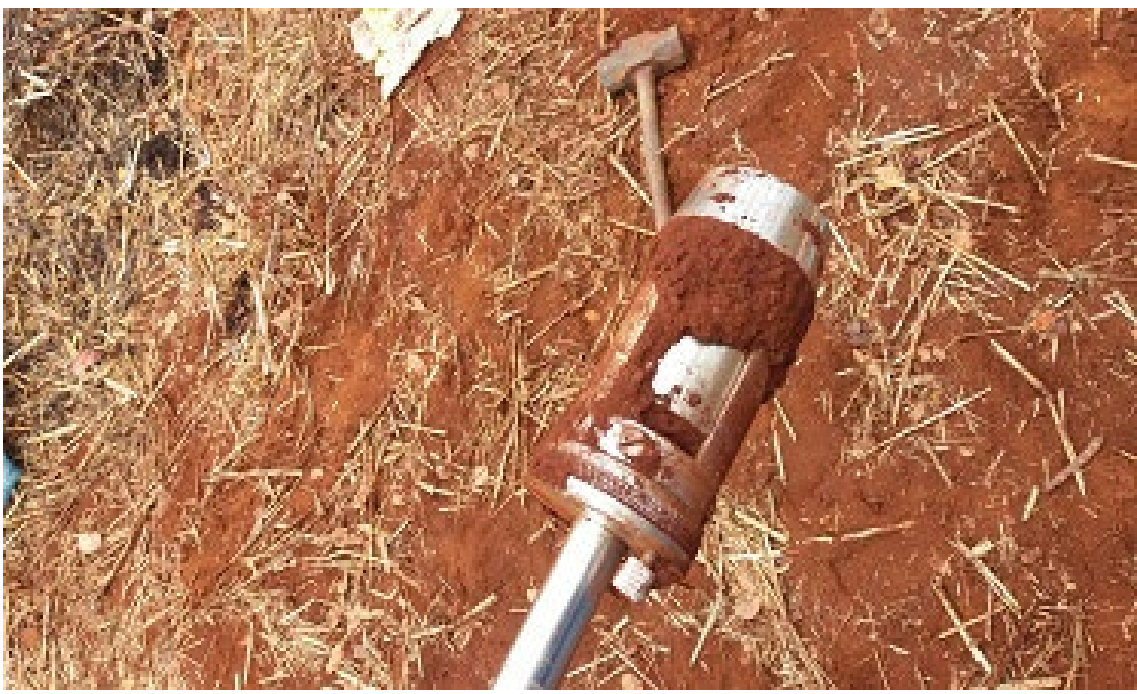

Fonte: Do autor (2018).

As coletas do solo foram realizadas durante o mês de agosto (período em que o solo se encontrava mais seco), novembro e janeiro para avaliar o grau de saturação do solo nas profundidades consideradas e para avaliar o grau de escoamento subsuperficial ao final do experimento. Os pontos de coletas foram georreferenciados e as variações de umidade foram espacializadas com auxílio do software Golden Surfer 9.0.

Para o cálculo do escoamento subsuperficial foi necessário obter a chuva acumulada no período do experimento, a área da encosta e a capacidade de água disponível (CAD). Com essas informações foi possível determinar o armazenamento médio de água no solo, no período avaliado.

Para definição do CAD utilizou-se a umidade média em milímetros durante os meses de agosto e janeiro, sendo janeiro representante da capacidade de campo (CC) e agosto do ponto de murcha (PM). Para isso, utilizou-se a equação a seguir. 


$$
\begin{gathered}
C A D=C C-P M \\
V=N C 1 * N C 2 * U M
\end{gathered}
$$

$V=$ Volume em $\mathrm{L} / \mathrm{m}^{3}$;

$N C 1$ = Número de cilindros por $\mathrm{m}^{2}$;

NC2 = Número de cilindros até um metro de profundidade;

$U M=$ Umidade média dos pontos coletados (mm).

O cálculo da umidade das amostras de solo foi realizado tendo como base a umidade (base massa) que é a relação entre a massa de água de uma amostra de solo e a massa das partículas e também, da umidade (base volume), como representada nas equações a seguir, modificadas pela Embrapa (1997, p. 7).

$$
\boldsymbol{\omega}=m w / m s
$$

Onde: $\boldsymbol{\omega}$ é a umidade; $m s$ é a massa do solo e $m w$ é a massa da água;

$$
\boldsymbol{\theta}=V w / V t=V w / V s+V a+V w
$$

Onde: $\boldsymbol{\theta}$ é a umidade volumétrica; $\boldsymbol{V} \boldsymbol{W}$ é o volume da água; $\boldsymbol{V}_{t}$ é o volume total; $\boldsymbol{V}_{s}$ e $\boldsymbol{V}_{\boldsymbol{a}}$ são respectivamente volume do solo e volume da amostra.

Para determinação do armazenamento médio durante o período do experimento utilizou-se o Balanço Hídrico Sequencial disponível para cálculo no site do Instituto Nacional de Meteorologia (INMET). O cálculo do balanço hídrico foi gerado com um CAD de $100 \mathrm{~mm}$ e posteriormente corrigido no software Excel para o CAD obtido no experimento, que foi de $180 \mathrm{~mm}$.

O resultado do armazenamento médio do período multiplicado pela área $\left(\mathrm{m}^{2}\right)$ resultou na média do volume de água armazenada no solo. Os dados de armazenamento na área para os meses em que não houve coleta de amostras de solos foram estimados com base na média de armazenamento mensal do período avaliado.

O cálculo do escoamento subsuperficial foi realizado a partir dos dados de umidade em litros, tanto na parte superior quanto inferior da 
vertente no mês de janeiro. O deslocamento foi calculado pela subtração do volume de água do topo pelo volume da base, que para ser calculado utilizou-se de maneira proporcional das variáveis da equação (3).

A velocidade do fluxo subsuperficial foi obtida entre o topo da vertente e a base da vertente em uma reta $\mathrm{A} \rightarrow \mathrm{B}$ considerando o tempo de deslocamento da água em segundos e a distância percorrida em centímetros, conforme o grau de inclinação da encosta no intervalo dado conforme equação (6).

$$
\mathrm{V}_{\mathrm{M}=}\left(\frac{\Delta \mathrm{s}}{\Delta \mathrm{t}}\right) \times \cos 3,7^{\circ}
$$

Onde: $\mathbf{V}_{\mathbf{M}}$ é a velocidade média; $\Delta \mathbf{s}$ é a distância (cm); $\Delta \mathbf{t}$ é o tempo (s); $3,7^{\circ}$ é a inclinação da vertente

A coleta de amostras de solos para avaliação textural foi obtida visando entender a capacidade de percolação de água nos mesmos. As amostras foram retiradas em um só dia em três pontos da vertente (topo, meio e base) a 30 e $60 \mathrm{~cm}$, totalizando seis amostras. A textura final resultou da média entre as amostras.

A análise textural foi realizada em um laboratório de solos, onde se determinou as frações argila, silte e areia das amostras. O método utilizado foi o do densímetro, desenvolvido por Bouyoucos (1954) citado por Kiehl (1979, p. 17). Os aparelhos utilizados foram: balança analítica, dispersor de solos, estufa de secagem, provetas de $1000 \mathrm{~mL}$, beckers de 50 $\mathrm{mL}$, solução de hidróxido de sódio $(\mathrm{NaOH})$, água destilada, densímetro de bulbo simétrico com variação de 0,999 a 1005 .

Foram desenvolvidos ainda, como parâmetros de análise, a densidade do solo (Ds), a densidade de partículas (Dp) e a porosidade total (Pt). A densidade e a porosidade total foram realizadas conforme a metodologia da Embrapa (1997, p. 16) e expressas pelas equações abaixo.

$$
\begin{aligned}
& D_{s}=M_{s} / V t \\
& P t=\frac{(1-D s)}{D p} \cdot 100
\end{aligned}
$$


Onde: $\mathbf{D}_{\mathrm{s}}$ é a densidade; $\mathbf{M}_{\mathrm{s}}$ é a massa seca, $\mathbf{V}_{\mathrm{t}}$ é o volume total; $\mathbf{P t}$ é a porosidade total e $\mathbf{D}_{\mathrm{p}}$ é a densidade de partículas.

A densidade de partículas foi realizada conforme metodologia de Blake e Hartge (1986, p.378 ) através da Equação (9).

$$
D_{p}=a /(50-b)
$$

Onde:

$\mathrm{D}_{\mathrm{p}-}$ Densidade de partículas;

a - Peso da amostra seca a $105^{\circ} \mathrm{C}$;

b - Volume de álcool etílico gasto

O volume de chuva acumulada no período foi transposto para a área da encosta, em L/ $\mathrm{m}^{2}$ multiplicando-se o volume total de chuva $(\mathrm{mm})$ pela superfície da área (m2).

O escoamento superficial foi calculado pelo volume escoado através da calha coletora $(\mathrm{mm})$. O volume de água captada na calha foi primeiramente transformado para $\mathrm{L} / \mathrm{m}^{2}$ e posteriormente multiplicado pela área total da encosta como explicitado na equação (10).

$$
E s=(V c \div A c) \times A e
$$

Es é o escoamento superficial (L); Vc volume total captado na calha (L); Ac é a área da calha (m2); Ae é a área da vertente (m2).

O volume total infiltrado foi obtido pela equação (11).

$$
\boldsymbol{V}_{\text {inf }}=(\mathrm{P}-\mathrm{Es})
$$

$\boldsymbol{V}_{\text {inf }}$ é o volume infiltrado (L); P é a precipitação (mm); Es é o escoamento superficial.

A diferença entre o volume da água infiltrada $\left(V_{\text {inf }}\right)$ e o volume de água armazenada no solo representou o volume de água efetivamente escoada para o lençol freático e/ou escoada lateralmente no sentido da inclinação da encosta. 
Resultados e discussões

A área utilizada para o experimento apresenta uma área de 16.657 $\mathrm{m}^{2}$ e seu volume foi calculado em $11.615 \mathrm{~m}^{3}$.

Quanto à litologia, pertence ao Grupo São Bento: Formação Serra Geral. O grupo São Bento compreende duas formações litológicas, sendo uma sedimentar formada por arenitos eólicos e outra vulcânica (Formação Serra Geral) ambas associadas à sinéclise da Bacia Sedimentar do Paraná. Segundo a CPRM (2002, p. 2), essa última formação teve sua denominação descrita pela primeira vez por White (1908) para formações eruptivas da Serra Geral em Santa Catarina entre Lauro Muller e São Joaquim. A mesma domina na área do experimento.

A Formação Serra Geral, segundo Hartmann (2014, p. 175), apresenta rochas vulcânicas que são representadas por 95\% de seu volume por "basalto, andesito basáltico e andesito, seguidas de riodacito e pouco mais de 5\% de riolito. A idade estimada para esta formação está entre 120 e 130 milhões de anos (Mulhmann, 1974) citado em (CPRM, 2002, p. 2).

A Figura 4 mostra a topografia da vertente que apresenta uma distância de 112 metros entre a parte superior e a base. A altitude máxima na parte superior é de 672 metros e da base 665 metros.

Figura 4 - Topografia da vertente.

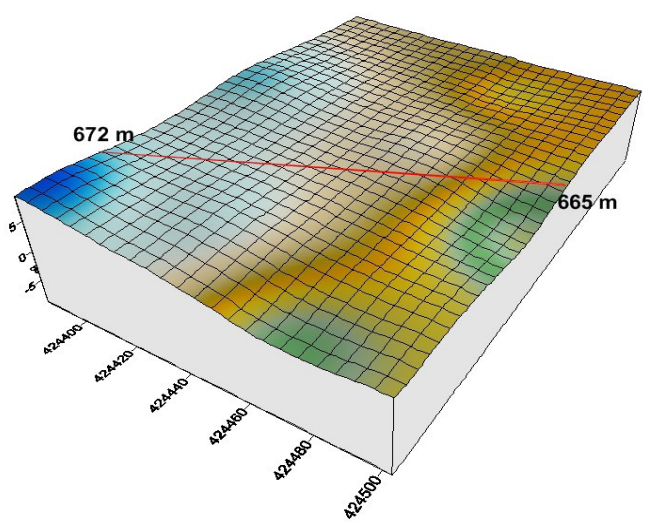

Fonte: Do autor (2018). 
O solo presente na vertente é um Latossolo Vermelho-Escuro distroférrico com textura Franco-Argilosa, conforme a classificação do Departamento de Agricultura dos Estados Unidos (USDA). A Tabela 1 destaca as suas principais características físicas.

Tabela 1 - Caracterização física do solo na área do experimento

\begin{tabular}{l|c|c|c|c|c|c|c}
\hline Textura & $\begin{array}{c}\text { Argila } \\
(\%)\end{array}$ & $\begin{array}{c}\text { Silte } \\
(\%)\end{array}$ & $\begin{array}{c}\text { Areia } \\
(\%)\end{array}$ & $\begin{array}{c}\text { Densidade } \\
(\mathbf{g} / \mathbf{c m}-\mathbf{3})\end{array}$ & $\begin{array}{c}\text { Densidade } \\
\text { Partícula } \\
(\mathbf{g} / \mathbf{c m}-3)\end{array}$ & $\begin{array}{c}\text { Porosidade } \\
\text { Total }(\%)\end{array}$ & $\begin{array}{c}\text { Condutividade } \\
\text { hidráulica } \\
\text { (cm/s) }\end{array}$ \\
\hline $\begin{array}{c}\text { Franco- } \\
\text { Argilosa }\end{array}$ & 39,5 & 21,4 & 39,1 & 1,17 & 2,85 & 52 & $5,6 \times 10-3$ \\
\hline \multicolumn{6}{c}{ Fonte: Do autor (2018). }
\end{tabular}

A porosidade total encontrada é compatível com solo de textura média no qual a porosidade varia de 52 a 47\%. A densidade é compatível com solo argiloso. A densidade de partículas mais elevada que a média é representada pela presença de minerais mais densos como o óxido de ferro e alumínio, esse fato é destacado também no trabalho de Reinert e Reichert (2006).

Quanto à textura obtida no experimento, Ribeiro et al. (2007, p. 3) encontraram valores semelhantes em Latossolo-Vermelho distroférrico de Lavras-MG, com argila na ordem de $41 \%$, silte $26,5 \%$ e areia $32,5 \%$.

A condutividade hidráulica não saturada apresentou valor médio conforme valores padrão descritos por (Dias, 2012, p. 55). Nesse solo, como em solo desenvolvido sobre gabro alcalino descrito por Sousa (2013), partículas de óxido de ferro se comportam como fração areia média a fina aumentando a sua porosidade.

A umidade entre os pontos de coleta apresentaram algumas variações entre suas respectivas profundidades. Essas variações são provocadas por micro-depressões no terreno em que a água tende a se acumular mais, e pontos ligeiramente mais compactados que outros, fazendo com que a água infiltre em velocidades diferentes.

Quando comparados os valores médios entre os meses de coleta percebe-se o aumento gradual da umidade entre as diferentes profundidades do solo conforme as chuvas se tornam mais frequentes.

A Tabela 2 mostra a variação média da umidade em função da profundidade e do mês, com destaque para o mês de janeiro que apresentou maior armazenamento entre os meses observados. 
Tabela 2 - Variação da umidade do solo conforme a profundidade e o mês.

\begin{tabular}{c|c|c|c}
\hline Mês & Umidade média (\%) $\mathbf{3 0} \mathbf{~ c m}$ & $\begin{array}{c}\text { Umidade média (\%) } \\
\mathbf{6 0} \mathbf{~ c m ~}\end{array}$ & Umidade média (\%) $\mathbf{1 0 0} \mathbf{~ c m}$ \\
\hline Agosto & 19,04 & 14,5 & 17,44 \\
\hline Novembro & 32,71 & 30 & 29,78 \\
\hline Janeiro & 26,63 & 29,1 & 31,53 \\
\hline
\end{tabular}

Fonte: Do autor (2018).

As Figuras 5 e 6 mostram a distribuição espacial da umidade na vertente nos meses considerados no experimento.

Em agosto, a $30 \mathrm{~cm}$ de profundidade nota-se a umidade mais acentuada no centro da vertente, na qual há uma ligeira concavidade do terreno e a delimitação acima e abaixo por curvas de nível, que facilitam a retenção da umidade.

No ponto 2, a $60 \mathrm{~cm}$ de profundidade (Figura 6), o solo apresenta um ligeiro aumento de umidade. Nesse ponto, há uma suave depressão do terreno provocada por concentração do escoamento superficial que flui para o centro da vertente. Na área restante, o solo apresenta uma melhor drenagem interna com distribuição mais homogênea da umidade.

Figura 5 - Umidade $30 \mathrm{~cm}$ (ago. 2017) Figura 6 - Umidade $60 \mathrm{~cm}$ (ago. 2017)
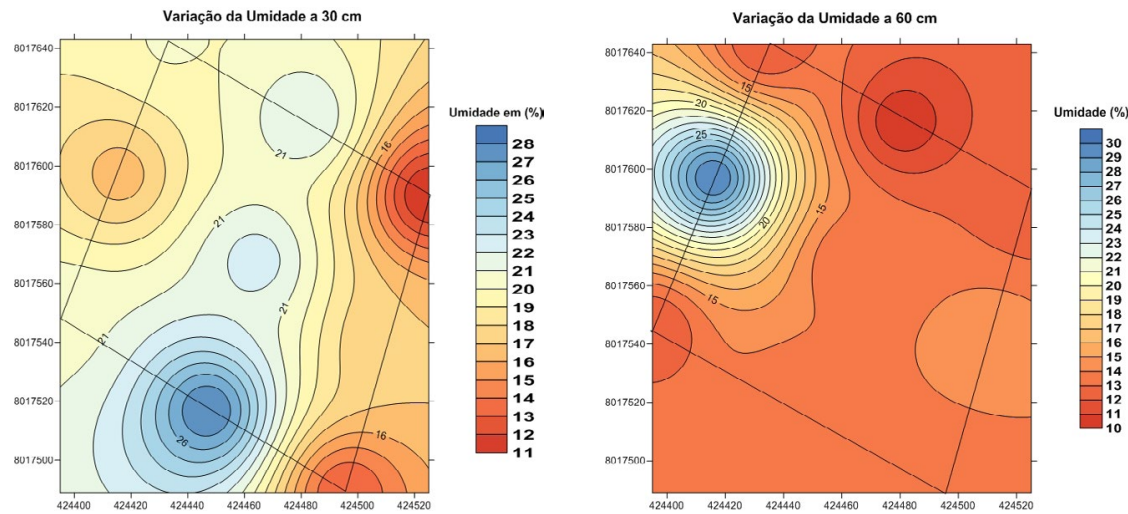
A Figura 7 representa a umidade aos $100 \mathrm{~cm}$ em que se percebe que a umidade sofre um acréscimo no setor leste da área, na qual há uma ligeira depressão no terreno e o solo é menos desenvolvido com menor intervalo para o lençol freático.

Figura 7 - Umidade $100 \mathrm{~cm}$ (ago. 2017)

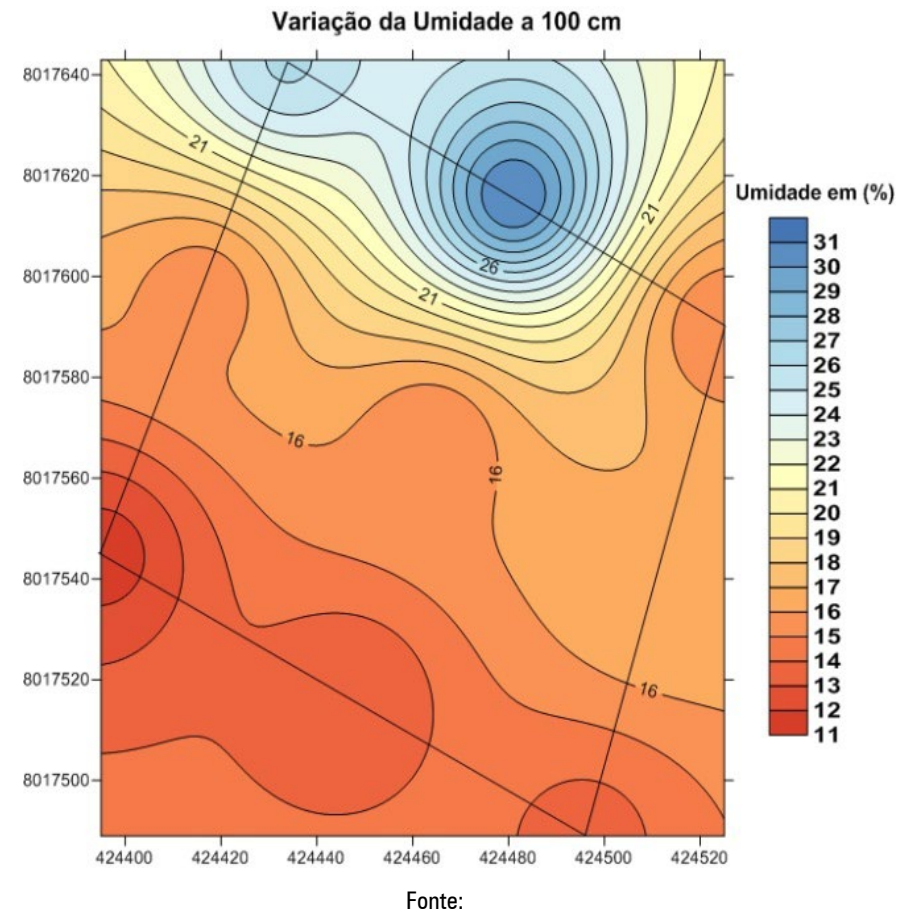

Em novembro, é possível notar um acréscimo de umidade até $30 \mathrm{~cm}$ em quase toda vertente (Figura 8). Enquanto a $60 \mathrm{~cm}$, sendo a infiltração insuficiente para umedecer o perifl, a umidade do solo fica mais concentrada em pontos de depressão do terreno e na parte mais baixa da vertente (Figura 9). 
Figura 8 - Umidade $30 \mathrm{~cm}$ (nov. 2017) Figura 9 - Umidade $60 \mathrm{~cm}$ (nov. 2017)
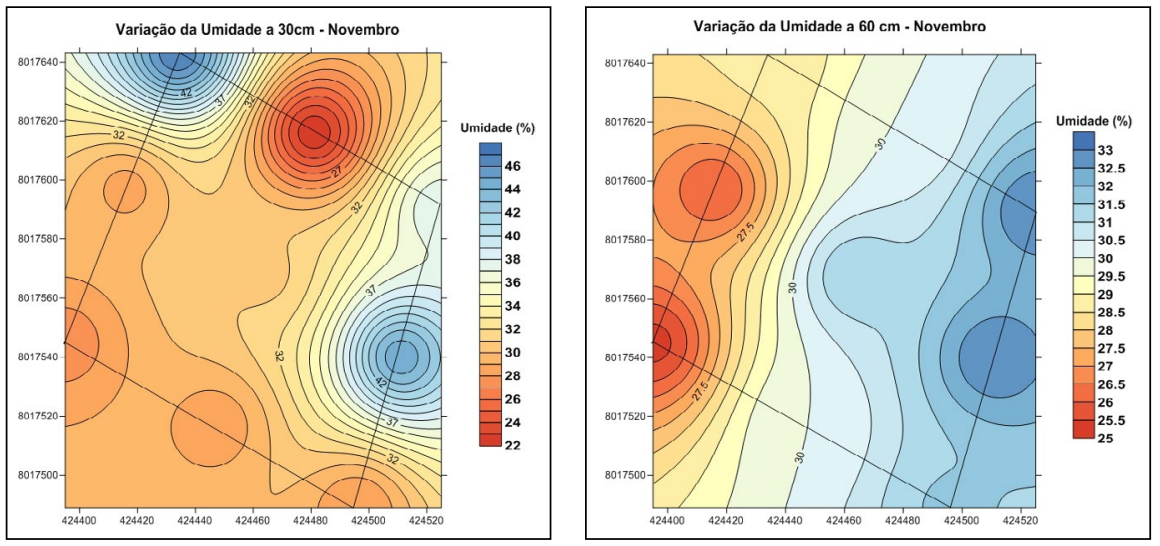

A Figura 10 mostra que aos $100 \mathrm{~cm}$ há um aumento maior nas porções leste e sul da vertente, caracterizando nesse período uma maior infiltração, bem como uma maior drenagem lateral em subsuperfície.

Figura 10 - Umidade $100 \mathrm{~cm}$ (nov. 2017)

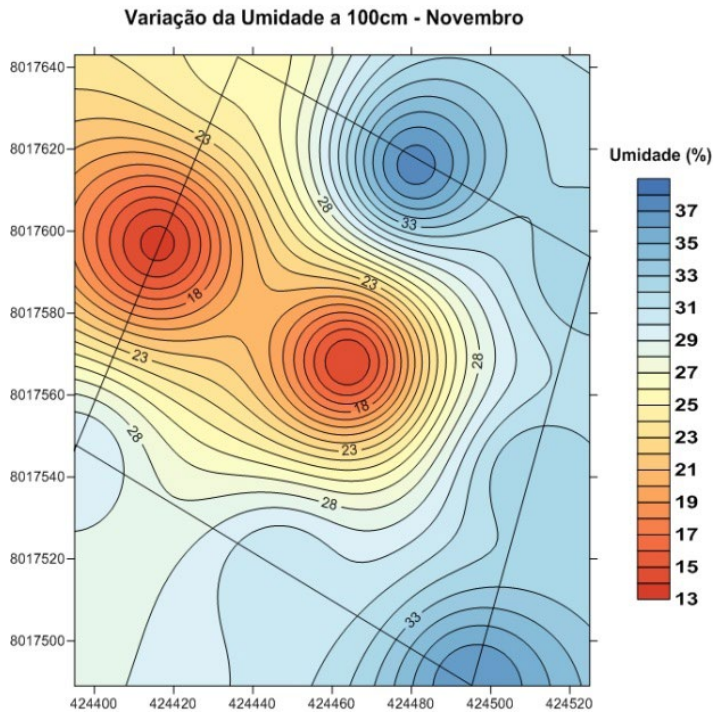


No mês de janeiro, o solo já apresenta umidade bastante elevada em todos os níveis de profundidade observados, com acréscimo a partir da média-alta vertente até a base. A distribuição da umidade pode ser visualizada nas Figuras de 11 a 13.

Figura 11 - Umidade $30 \mathrm{~cm}$ (jan. 2018). Figura 12 - Umidade $60 \mathrm{~cm}$ (jan. 2018)
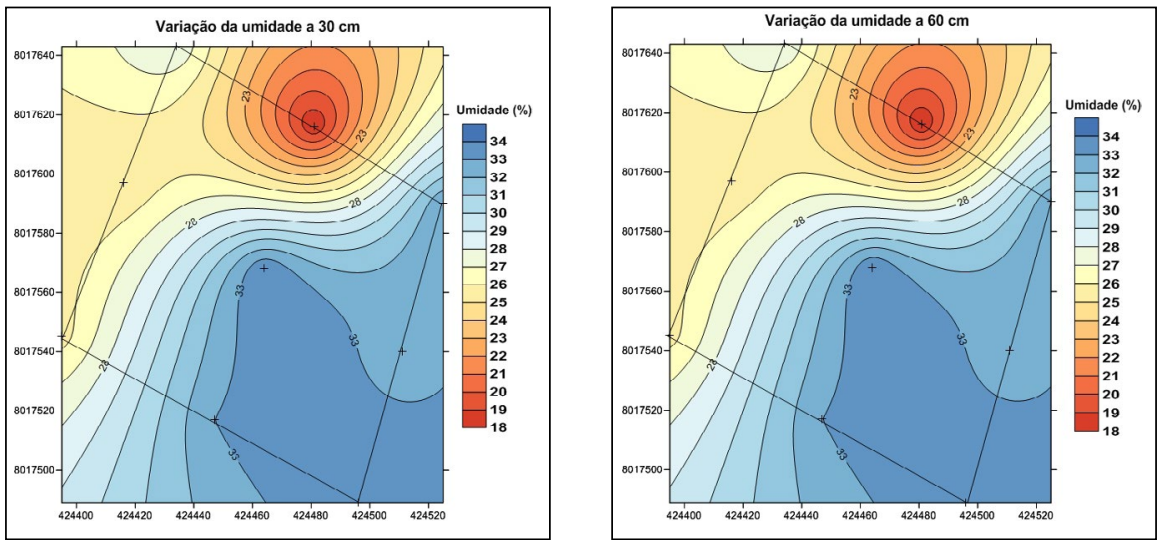

Aos $100 \mathrm{~cm}$ de profundidade, o solo apresenta um excedente hídrico com aumento da umidade em todos os setores da vertente e maior acúmulo na parte basal da vertente.

Figura 13 - Umidade a $100 \mathrm{~cm}$ (jan. 2018).

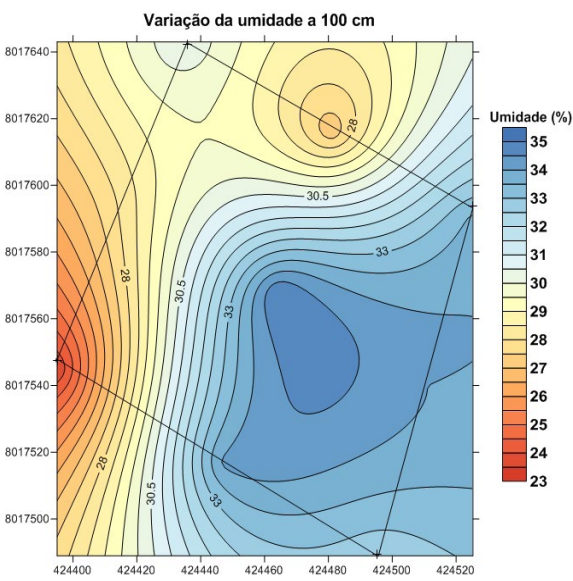


No Gráfico 1, é possível notar a elevação da umidade entre o mês mais seco e o mais úmido após uma acumulação pluviométrica de 858,6 mm.

Gráfico 1 - Variação da umidade durante o período de agosto de 2017 a janeiro de 2018

\section{Variação média da umidade do solo entre os meses de Agosto a Janeiro}

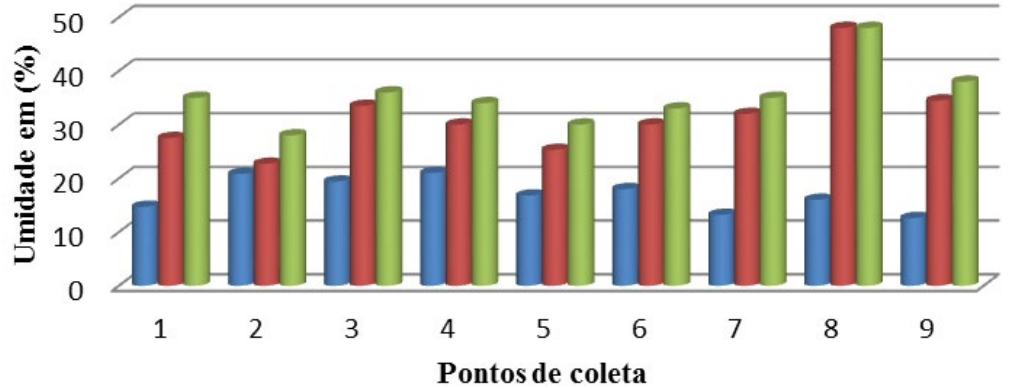

agosto Novembro Janeiro

Fonte:

Em novembro, a umidade já havia atingido o armazenamento pleno (Gráfico 2) e, em janeiro, há excedente hídrico mais acentuado, favorecendo a infiltração para o lençol freático e o deslocamento lateral em subsuperfície.

\section{Gráfico 2 - Relação CAD/Armazenamento}

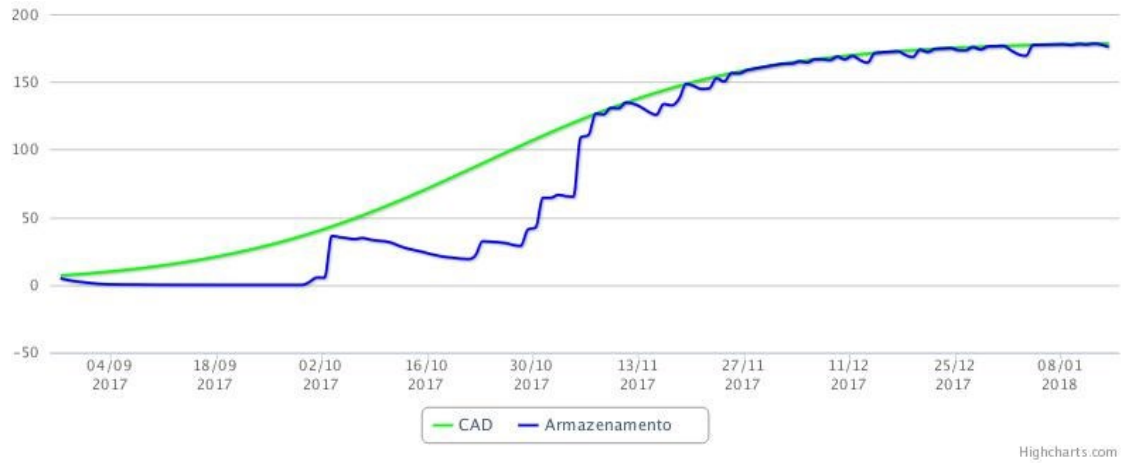

Fonte: Elaborado através de INMET/SISDRAGO. 
Quanto ao solo, ele oferece grande capacidade de infiltração e mesmo durante os períodos mais chuvosos a infiltração continuou a superar o escoamento superficial, mostrando que apresenta uma boa capacidade de armazenamento, que no presente estudo foi calculada em $180 \mathrm{~mm}$.

O armazenamento acumulado nos meses de agosto a janeiro estão representados na Tabela 3, enquanto a relação entre a infiltração e o escoamento estão representados na figura 16.

Tabela 3. Média e armazenamento de água no solo

\begin{tabular}{c|c|c}
\hline Mês & Média armazenada $(\mathbf{m m})$ & $\begin{array}{c}\text { Armazenamento (L) na } \\
\text { encosta }\end{array}$ \\
\hline Agosto & 3,8 & 62.523 \\
Setembro & 1,8 & 29.485 \\
Outubro & 23 & 383.597 \\
Novembro & 145,4 & 2.421 .141 \\
Dezembro & 178,9 & 2.979 .499 \\
Janeiro & 177,7 & 2.959 .390 \\
\hline Média & $\mathbf{8 4 , 4}$ & $\mathbf{1 4 . 7 2 6 . 0 5 8}$ \\
\hline
\end{tabular}

Fonte: Elaborado pelo autor (2018).

Gráfico 3 - Relação infiltração/escoamento

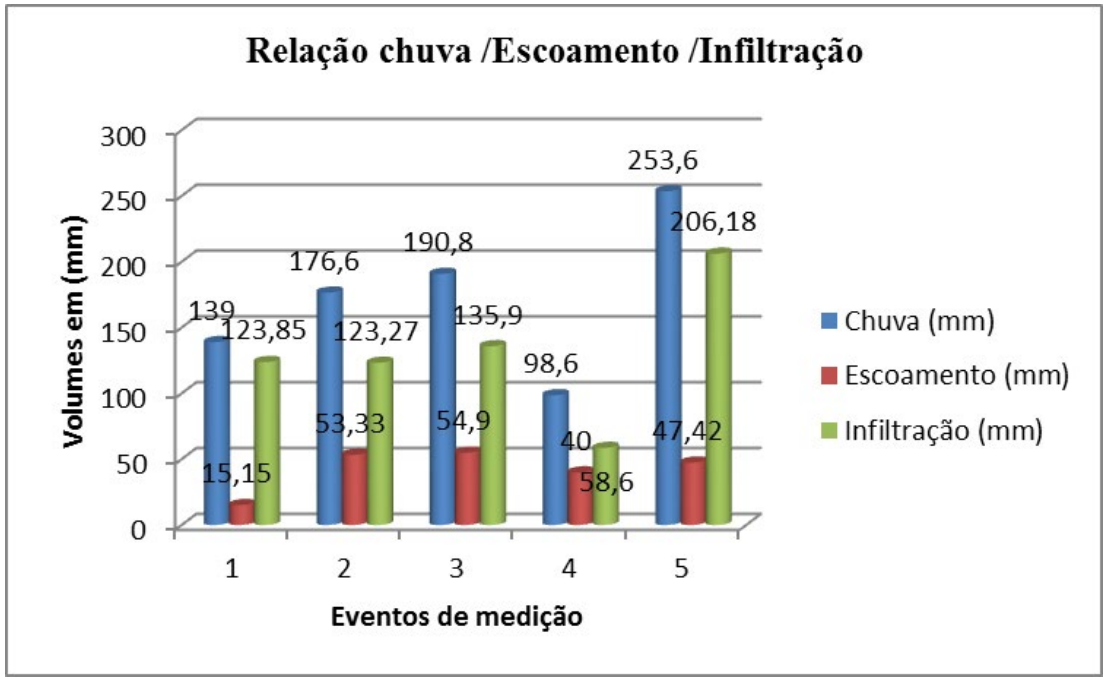

Fonte: 
As coletas que subsidiaram os cálculos da infiltração e do escoamento superficial estão representadas na Tabela 4, que mostra a precipitação acumulada na data da coleta, o volume escoado através da calha e o volume infiltrado através da calha.

Tabela 4 - Relação precipitação e volumes escoados e infiltrados.

\begin{tabular}{|c|c|c|c|}
\hline Chuva acumulada (mm) & $\begin{array}{l}\text { Volume escoado na calha } \\
\qquad(\mathrm{mm} / \mathrm{m} 2)\end{array}$ & $\begin{array}{l}\text { Volume infiltrado na } \\
\text { calha ( } \mathrm{mm} / \mathrm{m} 2)\end{array}$ & Período de coleta \\
\hline 139 & 15,15 & 123,85 & 01/08/2017 a 06/11/2017 \\
\hline 176,6 & 53,33 & 123,27 & 07/11/2017 a $19 / 11 / 2017$ \\
\hline 190,8 & 54,9 & 135,9 & 19/11/2017 a 05/12/2017 \\
\hline 98,6 & 63,1 & 35,5 & 06/12/2017 a $18 / 12 / 2017$ \\
\hline 253,6 & 47,42 & 206,18 & 19/12/2017 a $10 / 01 / 2018$ \\
\hline 858,6 & 233,9 & 624,7 & \\
\hline
\end{tabular}

Fonte: Elaborado pelo autor (2018).

O solo apresentou uma grande capacidade de armazenamento de água com $61,8 \%$ do total da precipitação, o escoamento superficial respondeu por $20,43 \%$ da precipitação com um coeficiente médio de escoamento de 0,23 , que caracteriza solo de textura Franca (Carvalho; Silva, 2006, p.98).

A infiltração para o lençol freático representou $17,76 \%$ do total. Tanto a infiltração profunda quanto o escoamento lateral em subsuperfície necessitam que o solo apresente excedente hídrico. Além do mais, segundo Carvalho e Silva (2006), a continuidade da infiltração vai atingir a zona saturada, entrando na circulação subterrânea e contribuindo para o armazenamento nos aquíferos.

A velocidade média de deslocamento da água em subsuperfície, considerando a inclinação de $3,7^{\circ}$ foi da ordem $1,74 \times 10^{-3} \mathrm{~cm} / \mathrm{s}$. Na Tabela 5 estão destacados os valores em litro e porcentagem do caminho da água da chuva na vertente. 
Tabela 5 - Distribuição da água da chuva na vertente entre agosto a janeiro.

\begin{tabular}{c|c|c}
\hline Elemento & Volume (litros) & Volume (\%) \\
\hline Escoamento superficial & 2.922 .857 & 20,444 \\
Armazenamento & 8.835 .635 & 61,780 \\
Infiltração profunda & 2.542 .398 & 17,770 \\
Escoamento subsuperficial & 858,102 & 0,006 \\
\hline Totais & $14.301 .748,102$ & $\mathbf{1 0 0}$ \\
\hline
\end{tabular}

Fonte: Elaborado pelo autor (2018).

\section{Considerações finais}

Este estudo, embora breve em termos de tempo de experimento, conseguiu demostrar que a metodologia é válida para estimar a dinâmica da água na vertente, bastando para isso considerar as peculiaridades inerentes em cada caso, como tipo de solo, características das vertentes e condições climáticas.

A análise dos resultados mostrou que além do teste da metodologia é possível com a aplicação da mesma, estimar as condições de uso e ocupação da vertente considerando a dinâmica que foi possível notar com os resultados. Por exemplo, o escoamento superficial e sua relação com potencial erosivo, a infiltração profunda (nos períodos de excedentes hídricos) para estimar a taxa de recarga do lençol freático, bem como o armazenamento, que possibilita planejamento do cultivo e irrigação. $\mathrm{Ou}$ seja, a metodologia pode ser aplicada para auxiliar em diversos fins ligados ao planejamento ambiental.

O presente estudo não teve a pretensão de solucionar questões relacionadas à dinâmica da água no solo, mas simplesmente gerar informações que possam efetivamente contribuir para o processo de discussão e provocar outros estudos que possam trazer à luz maiores esclarecimentos sobre o tema, uma vez que através do entendimento dos volumes de água efetivamente escoados superficialmente e infiltrados será possível entender o quanto de água está disponível para as plantas, o quanto contribui para a recarga do lençol freático, como se dá a dinâmica da água nos cortes de estradas e ferrovias e, em estudos que avaliem a demanda por água para os processos produtivos e para o abastecimento humano. 


\section{Agradecimentos}

Á Universidade Estadual de Goiás através da Pró-Reitoria de Pesquisa e Pós-Graduação e Pró-Reitoria de Planejamento e Desenvolvimento Institucional pela licença para a qualificação.

Ao Programa de Pesquisa e Pós-Graduação em Geografia da Universidade Federal de Goiás - CAJ/Jataí pelo apoio e pela concessão de Bolsa PNPD/CAPES no período de 01/02/2017 a 01/02/2018, sem a qual não teria sido possível desenvolver os experimentos de pesquisa.

\section{Referências}

BERTONI, J.; LOMBARDI NETO, F. Conservação do Solo. São Paulo: Ícone Editora, 1990. $360 \mathrm{p}$.

BLACKE, G. R.; HARTGE, K. H. Particle Density. In: KLUTE, A. (Ed.). Methods of soil analysis. Part 1. Madison. Wisconsin, USA: American Society of Agronomy, 1986. p. 377-382.

BRANDÃO, V. S. et al. Infiltração de água no solo. Viçosa-MG: Editora da UFV, 2006.

CARVALHO, D. F.; SILVA, L. D. B. Apostila de Hidrologia. Universidade Federal Rural, Rio de Janeiro, 2006. p. 11-115.

SERVIÇO GEOLÓGICO DO BRASIL. Ministério de Minas e Energia. Disponível em: $<$ http://www.cprm.gov.br/publique/media/gestao territorial/geoparques/coluna white/colunaestratigrafica.html.>. Acesso em: 20 dez. 2017.

DIAS, C. O. Determinação da condutividade hidráulica de solos não saturados. 2012. 240 f. Dissertação (Mestrado) - Programa de Pós-Graduação em Engenharia da Construção Civil, Universidade Federal do Paraná, Curitiba, 2012.

EMBRAPA. Manual de Métodos de Análise de Solo. Rio de Janeiro: Centro Nacional de Pesquisa de Solos, 1997.

HARTMANN, L. A. A história natural do Grupo Serra Geral desde o Cretáceo até o Recente. Ciência e Natureza, Santa Maria, v. 36, n. 2, p. 173-182, 2014.

COSTA, E. T.; PAULINO, H. B. APP Triângulo Textural: aplicativo para celulares. ANO. Disponível em: < https://www.sbcs.org.br/?noticia_geral=triangulo-texturalaplicativo-para-celulares $>$. Acesso em: 25 jan. 2018.

INSTITUTO NACIONAL DE METEOROLOGIA. Balanço Hídrico. ANO. Disponível em: <http://sisdagro.inmet.gov.br/sisdagro/app/monitoramento/bhs > . Acesso em: 02 fev. 2018.

KIEHL, E. J. Manual de edafologia: relação solo-planta. São Paulo: Agronômica Ceres, 1979. $262 \mathrm{p}$.

LEPSCH, I. F. 19 lições de pedologia. São Paulo: Oficina de textos, 2011. 793 p. 
POTT, C. A. Determinação da velocidade de infiltração básica de água no solo por meio de infiltrômetros de aspersão, de pressão e de tensão, em três solos do estado de São Paulo. 2001. Dissertação (Mestrado) - Instituto Agronômico, Campinas, 2001.

REINERT, D. J.; REICHERT, J. M. Propriedades físicas do solo. Disponível em: $<$ https://www.agro.ufg.br/up/68/o/An lise da zona_n_o saturada do solo texto.pdf> . Acessado em: $30 \mathrm{dez} .2017$.

RIBEIRO, K. D. et al. Propriedades físicas do solo influenciada pela distribuição dos poros em seis classes de solo na região de Lavras-MG. Ciência e Agrotecnologia, Lavras, v. 31, n. 4, p. 1167-1175, jul./ago. 2007.

SOUSA, F. A. de. A contribuição dos solos originados sobre granitos e rochas alcalinas na condutividade hidráulica, na recarga do lençol freático e na suscetibilidade erosiva: um estudo de caso na alta bacia hidrográfica do rio dos Bois em Iporá-GO. 2013. 207 f. Tese (Doutorado) - Instituto de Geografia, Universidade Federal de Uberlândia, Uberlândia, 2013.

VALENTE, O. F.; GOMES, M. A. Conservação de nascentes: hidrologia e manejo de bacias hidrográficas de cabeceira. Viçosa: Editora Aprenda Fácil, 2005. 210 p.

Flávio Alves de Sousa - Possui graduação em Geografia pela Universidade Estadual de Londrina, mestrado em Ambiente e Apropriação do Espaço do Cerrado pela Universidade Federal de Goiás e doutorado em Geografia pela Universidade Federal de Uberlândia. Pós-doutorado em Geografia pela Universidade Federal de Goiás, regional de Jataí. Atualmente é professor da Universidade Estadual de Goiás. (iD) https://orcid.org/0000-0002-0770-9966

Recebido para publicação em 03 de dezembro de 2018 Aceito para publicação em 15 de janeiro de 2019 Publicado em 15 de março de 2019 